\title{
NECESSIDADE E INDIVIDUAÇÃO ${ }^{1}$
}

Iray CARONE ${ }^{2}$

- RESUMO: A crítica das modernas sociedades capitalistas passa necessariamente pela crítica do indivíduo - a separação entre psique e cultura não é mantida quando uma forte tendência para uma sociedade unidimensional submerge o particular no universal totalitário. Por esse motivo, o conhecimento da subjetividade humana não é um objetivo exclusivo de psicólogos adentrando na imanência psíquica. Os filósofos críticos têm a mesma intenção, também - e a prova são os estudos frankfurteanos sobre o autoritarismo na década de 1940. Apresentaremos alguns aspectos da obra filosófica de Agnes Heller (1929 -) relacionados com a questão do indivíduo e a urgência de construir os fundamentos teóricos de uma ética que possa servir de guia para a práxis humana nas nossas sociedades modernas.

- UNITERMOS: Necessidade; indivíduo; ética; práxis.

Na década de 1940, Adorno e outros cientistas de Berkeley apresentaram, em A personalidade autoritána, uma espécie de tipologia psicológica das tendências ideológicas dos sujeitos estudados, com uma justificativa melancólica:

Em outras palavras, aqueles que criticam a tipologia não devem esquecer que grande número de pessoas não são já, seria melhor dizer que nunca foram 'indivíduos', no sentido que lhe dá a filosofia tradicional do século dezenove...

Temos razões para buscar tipos psicológicos porque o mundo em que vivemos está tipificado e 'produz' diferentes tipos de pessoas. Apenas mediante a identificação dos traços esteriotipados do homem moderno, e não negando a sua existência, se pode contrariar a tendência perniciosa para a classificação e agrupação gerais. (1965, p. 698)

Ou seja, não é por falha metodológica ou erro conceitual que $A$ personalidade autoritánia acabou enquadrando os sujeitos estudados em tipos, mas sim, porque as forças sociais prevalecentes estão a impedir a individuação, submergindo o particular no universal. A tipologia pretende ser, portanto, uma denúncia do existente. Há um

1. Pesquisa realizada no Departamento de Filosofia da New School for Social Research (New York) sob a orientação da filósofa Agnes Heller.

2. Departamento de Psicologia da Aprendizagem, Desenvolvimento e Personalidade do Instituto de Psicologia da Universidade de São Paulo. 
processo de desindividuação em marcha que converte as psicologias individuais e até mesmo a Psicanálise (na medida em que supõe a identificação e a formação do ego como realidades) em belos anacronismos.

Vale perguntar, agora, quais são os mecanismos sociais e psicológicos que produzem essa forma sofisticada e última da alienação que é o não-indivíduo ou a não-individualidade. Pressuposto ou conclusão tirada dos dados da pesquisa, é preciso saber como é que as formas contemporâneas de controle social adquiriram o poder de eliminar o ego da História, último reduto da negação.

Horkheimer (1970) buscou explicar o processo social desindividualizador através da absolescência da unidade familiar, tornada inócua como mediação ideológica na "sociedade sem pai" da modernidade capitalista. Subjetividades pré-edipianas, puros "ids" gravitando no Todo, os indivíduos da sociedade burguesa atual são os exemplos mais refinados de uma brutal heteronomia.

É o velho tema marxista da alienação que está em jogo. São os Manuscritos de Panis (Marx, 1980) retomados para iluminar as nossas modernas enfermidades, em níveis mais profundos. Aliás, a própria Psicologia é vista como parte dessa doença, com a sua sucessora, a psicoterapia (Adorno, 1967, p. 76).

Exagero ou não exagero, a questão ainda impressiona. Basta verificar que ela esteve soberanamente presente na crítica da cultura americana dos anos 70. Ou então, provocando alguma fúria de competentes feministas atuais, como Jessica Benjamin (1978), que pressentem um ranço conservador nas investidas contra o novo narcisismo.

Tanto o problema quanto a forma de analisá-lo dependem, no caso de Frankfurt, das categorias psicanalíticas tornadas categorias negativas ou críticas face à nova subjetividade burguesa.

Lembremos, entretanto, que o problema tem fortes raízes marxistas. Trata-se de recolocar a questão da alienação da essência humana no momento presente. Recorremos à obra de Heller porque ela permite um rigoroso retorno ao jovem Marx, ao mesmo tempo que facilita a volta à modernidade capitalista. Lukács disse que os livros A ética de Aristóteles e $O$ homem da Renascença são monografias históricas que Heller escreveu sobre estágios da alienação humana, retratando períodos nos quais:

(...) existia um mínimo de alienação e estava reduzida ao mínimo a distância entre as características essenciais do gênero humano e a sua riqueza individual. (Lukács, 1977)

Os demais livros, de uma maneira ou outra, estão a falar de nosso presente: Everyday life (Heller, 1984c), Beyond justice, general Ethics (1987g), The power of shame (1985) etc.

Agnes Heller elaborou conceitos e teorias que foram, até certo ponto, desprezados pela própria história do marxismo: as necessidades, os instintos, os sentimentos, a personalidade. A ausência desses conceitos teóricos explica, em parte, o aparecimento dos vários freudo-marxismos face aos níveis mais profundos da alienação no plano da subjetividade. 
Nosso objetivo é, pois, o de apresentar a teoria do indivíduo, de Heller, a partir de sua análise do "sistema de necessidades" engendrado pelo capital. Equivale a repensar a questão levantada por Adorno, em A personalidade autoritária (1965), negando, entretanto, o seu conteúdo psicanalítico. O resultado será, por certo, absolutamente outro.

A análise da situação da individualidade no momento presente carrega consigo a pergunta sobre o futuro - quais são as nossas reais alternativas políticas de transcendência?

\section{O método de trabalho}

Dado o problema da pesquisa e colocado para Agnes Heller, adotamos o seguinte procedimento:

a) entrevistas, gravadas ou não, com a filósofa, a respeito de questões relativas ao plano de pesquisa;

b) pesquisa bibliográfica, tendo como base o currículo de Agnes Heller e as referências diretas ou indiretas ao seu trabalho, nas principais revistas especializadas da França, Itália, Alemanha e Estados Unidos.

Como a obra de Heller é ampla, variada e rica, tomamos como eixo da análise dos textos o tema da pesquisa: Necessidade e individuação. Os conceitos principais foram discutidos com a filósofa, para maior esclarecimento, após prévia leitura dos textos indicados por ela.

Utilizamos, de modo geral, traduções para o inglês. Agnes Heller está escrevendo, atualmente, na língua inglesa. No entanto, seus primeiros trabalhos, da década de 60 , foram escritos em húngaro ou alemão. As obras da autora estão arroladas no item seguinte.

\section{As obras de Agnes Heller}

Vejamos como ela mesma se apresenta no seu Curiculum Vitae:

Born 1929, first married to Istvam Hermann (1949), later to Ferenc Feher (1962); two children: Suzanna Hermann and George Feher. Student of G. Lukács since 1947, later his Ph.D. student and assistant professor in his department. First editor of the postwar Hungarian Philosophical Journal (1955-1956). Dismissed from academic position together with G. Lukács for political reasons after the Hungarian Revolution. Several years spent in grammar school teaching and banned from all publications.

1968: Protest against the Soviet invasion of Czechoslovakia, renewed political and police harassment. 
1973: on special decision of party authorities all academic positions lost again, political unemployment between 1973 - 1977.

1977: Emigration to Austrália.

Está radicada atualmente nos Estados Unidos e trabalhando no Departamento de Filosofia da New School for Social Research, New York.

Na lista de publicações, Agnes Heller apresenta 31 livros e 99 "theoretical papers", bem como centenas de artigos e entrevistas para jornais e revistas.

De modo geral, escreveu duas monografias históricas: The Renaisssance man e Aristótle's ethic. Além disso, obras de caráter mais geral: Every life, towards a marxist theory of value, A theory of History, General ethics, The power of shame, Beyond justice, Radical philosophy.

Obras que ela mesma denomina de Antropologia Social e que nos interessam de modo particular: The theory of need in Marx, On instincts, A theory of feelings. A sua lista de publicações inclui também escritos políticos, em geral, em co-autoria com Ferenc Feher e alguma colaboração na área de Estética.

A mesma variedade de temas vamos encontrar nos artigos teóricos: desde Epistemologia até Política. O interesse central da autora parece ser a Ética, não só porque esse tema estava a exigir uma reflexão teórica mais profunda dentro da tradição marxista, mas também por causa das suas implicações políticas.

Embora não tenha dedicado nenhum livro para o desenvolvimento de uma "teoria da personalidade", ela está, sem dúvida alguma, implicada nos seus trabalhos teóricos de maior envergadura. É o que tentaremos explicitar no que segue.

\section{A teoria do indivíduo de Agnes Heller}

\subsection{Os instintos}

No ensaio sobre os instintos (1983), Agnes Heller prevê uma seqüência temática a ser desenvolvida, de modo a dar conta de uma "Antropologia Social".

1. Os instintos

2. A teoria das sensações

3. A teoria das necessidades

4. A teoria da moral

5. A teoria da personalidade

6. A teoria da história

Não escreveu ainda sobre personalidade, dando prioridade à teoria da moral ou Ética Geral. Os conceitos de indivíduo, individualidade e personalidade estão topica- 
mente nos livros Everyday life (1984c) e The power of shame (1985), bem como em vánios artigos teóricos.

Por que Agnes Heller se interessou em escrever sobre temas que ela mesma denominou de Antropologia Social (não no sentido técnico de expressão)?

A autora é explícita nas suas intenções ao tentar uma interpretação pessoal do que são os instintos, por exemplo, através de uma análise crítica de várias teorias científicas (a seu ver, penetradas de ideologia) a esse respeito:

A minha escolha de etólogos e antropólogos como fontes científicas do meu conceito de instintos não foi instigada - e não foi intencionalmente - simplesmente pela sua descrição de fatos empíricos e experimentais de um modo isento de contradições. Na minha escolha, fui levada conscientemente, tenho de sublinhar - pelas minhas concepções e valores filosóficos (que são inseparáveis). Procurei um conceito de instintos que, por um lado, corresponde aos fatos revelados pela ciência empírica e experimental no seu nível presente mas que, ao mesmo tempo, também satisfaz as minhas hipóteses filosóficas, teóricas e de valor. (1983, p. 31)

A seguir, explicita as suas hipóteses e valores que são, sem dúvida alguma, baseados nos Manuscritos de Panis (Marx, 1978) a essência humana ou a espécie humana é histórica, plástica, com infinitas potencialidades. Daí a discussão do instinto, de um ponto de vista marxista.

Define, então, instinto como

os mecanismos de comportamento ou as coordenações motoras compulsórias que são específicas da espécie e, ao mesmo tempo, específicos de ação herdados, por meio do código genético, desencadeados por estímulos internos e externos e que desempenham um papel preponderante na preservação da espécie dentro de um certo estágio do desenvolvimento do organismo e que ultrapassam a inteligência da espécie em questão, do ponto de vista deste valor seletivo positivo. (1983, p. 40)

Em relação a essa definição de instinto, como caracterizar a espécie humana? A autora diz claramente: o homem não é um ser guiado pelo instinto, mas apenas por vestígios de instintos! (1983, p. 43). Se são características da essência humana a liberdade, a socialidade, a consciência, a objetivação e a universalidade, então o homem tende mais e mais a ser menos animal, através do próprio processo de se objetivar historicamente.

Não quero discutir as hipóteses de Heller e a teoria dos instintos que lhe parece ser compatível com seus pressupostos. Interessa-me compreender a sua finalidade ao tentar constituir uma Antropologia Social fundada filosoficamente nos Manuscritos de Panis (Marx, 1978) e numa ética marxiana.

Parece-me que a autora não busca apenas desenvolver o que não está desenvolvido, mas simplesmente indicado nos Manuscritos: necessidades, instintos, sensações, sentimentos etc. Ela quer respostas às perguntas sobre o atual estágio da essência histórica do homem, pelas suas inúmeras e contraditórias objetivações culturais - e, nesse sentido, a Antropologia é indispensável, embora não suficiente para responder ao "como". Além dessa espécie de avaliação via objetivações 
históricas, é possível julgar o futuro. O que está em causa é a eliminação da alienação e a realização das individualidades (1983, p. 148).

É preciso ter clareza, entretanto, sobre o âmbito das análises hellerianas em tópicos que poderiam ser facilmente classificados de "psicológicos" ou "antropológicos". A sua perspectiva é sempre filosófica e política, embora o objeto de análise possa ser exatamente o mesmo da Psicologia e da Antropologia (1983, p. 148).

Outra questão nos inquieta diante das investigações de Heller a respeito de necessidades, instintos e sentimentos: como ela articula o plano de espécie com o plano do individual e do subjetivo?

É interessante observar que no ensaio sobre instintos, Agnes Heller se aproxima decididamente da chamada "terceira tendência " em psicologia: a corrente humanista de Maslow e outros. Diz que há, todavia, "uma diferença filosófica básica entre os nossos conceitos que, em última análise, reside nas nossas diferentes interpretações da essência da espécie. Em minha opinião, não há essência da espécie, natureza humana ou substância inerentes a todos os indivíduos. Não há dois seres ocultos no homem, um autêntico e outro inautêntico, e a função das objetivações não é facilitar o desenvolvimento do inautêntico ou impedir o desenvolvimento do autêntico". (Heller, 1983, p. 136-137) Embora rejeite a óbvia naturalização da essência humana na teoria psicológica de Maslow, Heller vê pontos em comum entre essa teoria e a tipologia por ela desenhada na obra Everyday life (1984 c): a distinção entre a pessoa particularista e o indivíduo. É o que veremos a seguir.

\subsection{Particularidade e individualidade}

Ferdinando Adornato afirmou que a contribuição original de Heller ao marxismo contemporâneo é ter colocado no centro da reflexão teórico-prática a temática do indivíduo e que o atual período histórico

(...) impōe-nos a emergência da temática do indivíduo, como uma temática que deve ser enfrentada de modo novo, sob pena da decadência de nossas funções hegemônicas. Nessa pesquisa nova, temos de acertar as contas com a teoria burguesa do individualismo, com a sua tradição assim como com o conceito de pessoa que é próprio da tradição católica. (1982 b, p. 157-158)

É preciso que se diga: tematizar o indivíduo não é simplesmente remeter a reflexão teórica para o campo da Psicologia. A questão do indivíduo é muito mais complexa e eminentemente ético-política, embora seja também psicológica.

O que é realmente novo em Heller é que ela enfrenta a temática do indivíduo sem apelar para categorias psicanalíticas. É hora de perguntar quem é o indivíduo e não reduzi-lo a uma expressão ou mera personificação dos anseios e desígnios do "capital" ou de "uma atividade abstrata e um estômago" (Fonseca, 1989, p. 151). Na obra de Heller, a elaboração de uma teoria do indivíduo não é independente da 
retomada dos Manuscritos parisienses e, sobretudo, da construção de uma ética enorme vazio da tradição marxista (1987).

Cabe, no entanto, a pergunta de que Marx estaria a reduzir o indivíduo a meras personificações do capital e do trabalho ou, então, a falar da redução das individualidades, da redução concreta das vidas individuais sob o capital: “...a individualidade entre as massas é de longe menos integrada e persistente do que entre os componentes da chamada elite. Por outro lado, a elite esteve sempre mais preocupada com as estratégias de lucro e conquista do poder. O poder social é hoje mais que nunca mediado pelo poder sobre as coisas. Quanto mais intensa é a preocupação do indivíduo com o poder sobre as coisas, mais as coisas o dominarão, mais lhe faltarão os traços genuínos e mais a sua mente se transformará num autômato da razão formalizada" (Horkheimer, 1976, p. 140-141).

Mas não tem sido dito que a sociedade burguesa foi a que mais desenvolveu a multiplicidade das individualidades? Vejamos o que Heller diz sobre essa questão:

Bourgeois society really did develop individuality to a great extent. This is observed best in the Renaissance, historically the moment when the evolution of this society began. Later, individuality continued to acquire completely new properties, too, including intensified inwardness, a fact seismologically signalled by flourshing music and lyric poetry. Only bourgeois society dissolving natural communities was able to create the possibility for the individual to raise himself to any height, to direct his own fate - an achievement symbolized by the personality of Napoleon. But at the time, bourgeois society was the very society which, by subordinating the individual to his class and subjecting him to the laws of economics, ultimately frustrated the possibilities created by bourgeois society itself; bourgeois society dragged the free individual into the slavery of alienation to such an extent that de facto he sank very much below the level of individuals in previous epochs. (1973b, p. 11-12)

Ou seja, a sociedade burguesa liberou o indivíduo para melhor dominá-lo.

Como é que Heller analisa as formas pelas quais a sociedade burguesa moderna aliena a individualidade e as estratégias de sobrevivência psíquica ou de recuperação da singularidade?

Os processos sociais, por meio dos quais as férreas leis econômicas são mediatizadas, afetando, de alguma maneira, o plano da subjetividade humana, não impede, segundo Heller, o surgimento de individualidades ou personalidades fortes, mais conscientes e livres que outros homens. Ou seja, mais alienação não significa ausência de individualidade na sociedade burguesa.

Há dois processos de objetivação ou dois processos de desenvolvimento da personalidade: aquele que resulta na pessoa particularista e o que resulta no indivíduo. Veremos em que consiste esta diferença e como é que se dão os dois processos de objetivações, segundo as categorias interpretativas de Heller.

De qualquer modo, é impossível caracterizar a pessoa particularista e o indivíduo como meras unidades que se expliquem a si mesmas. É a maneira pela qual se relacionam com o mundo social a que pertencem (grupos, comunidades naturais ou de escolha, sociedades mais amplas) que servirá de critério distintivo. Isso nos remete à ética, pois as convivências sociais são reguladas pelos costumes, normas e opinião 
pública. Daí que o modo de viver da pessoa particularista equivale ao individualismo; o contrário sucede com o indivíduo, que atinge uma universalidade singularizada no seu modo de agir social.

O problema é que, muitas vezes, se coloca como a origem do indivíduo a emergência do individualismo. Na verdade, em Heller, o homem só se converte em indivíduo quando transcende conscientemente os particularismos, deixando de ver o Outro (a sociedade, a espécie humana) como mera externalidade - ele é o outro e a si mesmo também: 'The individual man is a man who synthesizes the factual uniqueness of his individuality and the universality of his species within himself (1970, p. 212).

Historicamente, a era de Péricles, a Atenas do século $V$, foi o momento em que se tornou possível o mais completo desenvolvimento da essência do homem, da sociedade e das individualidades, porque a polis já anunciava a ruptura com as comunidades naturais primitivas, com os vínculos tribais e relações de casta.

A emergência do indivíduo se refletiu, de modo esplêndido, na grande tragédia grega, na comédia e no pensamento teórico da Ática voltado para o homem e para a moral. O subjetivo ganhou, finalmente, os seus grandes autores.

Podemos afirmar que, sin el inagotable matenial proporcionado por las tragédias euripideas, Aristóteles no habria podido analizar con tanta profundidad los principios interiores de la acción humana: la voluntad y la liberdad, la refléxion y la decisión. (Heller, 1984a, p. 58)

O individualismo, na segunda fase da mesma era, ganhou foros de cidadania, teve os seus adeptos e ideólogos na sofística tardia. Modo de comportamento compatível com a crise da polis, ele expressa com energia as aspirações do cidadão pela autonomia absoluta. 'La personalidad individual que se ha formado en el seno de la comunidad de la polis griega de manera consciente y ética no tarda en hacer saltar los esquemas de la ciudad misma; se rebela contra la comunidad, que se percibe ya como un obstáculo y reinvidica el derecho de vivir la propria vida de manera absoluta; reinvidica el individualismo, en suma' (Heller, 1984a, p. 35). Antifon e Sócrates encarnam, neste momento histórico, duas moralidades que militam pela valorização do indivíduo de distintas maneiras.

Essas moralidades têm um ponto principal de confronto: o agir da pessoa particularista faz da sociedade o meio de realizar as suas necessidades, que se convertem em greed; o agir do homem individual busca a identificação com a sociedade através da diferença individual. Aparente dualismo ou dicotomia mecânica - trata-se da dialética do próprio todo que engendra um e outro comportamentos.

Voltemos, agora, para os nossos tempos. Como é a individualidade burguesa?

Diz Heller: "Essa individualidade burguesa - não a chamamos ainda de individualismo - expressava-se na dissolução das velhas hierarquias de valor, com a possibilidade de o indivíduo organizar para si uma escala de valores e de carecimentos própria" (1982b, p. 157). Ela busca a especificidade do modo de ser burguês através 
da especificação de nossa época pela perspectiva das necessidades, ou seja, 'from that of need-creation, need-perception, need-distribution and need-satisfaction' (1988, p. 14). Com a industrialização, capitalização e democratização crescentes, a moderna sociedade burguesa tende a criar uma enorme força motivacional de insatisfação. Quais são os efeitos subjetivos, propriamente psicossociais, criados por essa força motivacional externa? Que aspirações, alegrias, sofrimentos e expectativas são forjados nessa máquina infernal?

Os tempos pré-capitalistas eram, sem dúvida, mais calmos: o desenvolvimento das necessidades estava limitado por um conjunto de normas de conduta ditadas pela própria sociedade. O capitalismo desmantelou todos os sistemas de conduta e o sistema individual de necessidades expandiu sem limites. 'And given that our life is a limited enterprise, we not only live, we also die in dissatisfaction' (1985, p. 307).

A individualidade burguesa está, portanto, marcada por profunda e contínua insatisfação, mas o consumismo é um redutor dessa insatisfação.

If a salesgirl is watching the Marilyn Monroe Story on TV, the gap between her own situation and her dreams of be coming a famous actress is absolutely unbridgeable. But should she be concentrating on the dress, rather than on the career of the actress, it is not out of her reach to buy such a dress, al least similar in colour and in style for herself. If one's ambition is not related to power or fame but to consumables, dissatisfaction as a basic emotional background feeling will not disappear, but one can, at least for a few moments, feel like a queen or a king if one uses the same brand of soap as Sophia Loren, the same necktie as Rockefeller or the same cap as Lenin. (1985, p. 307)

\section{Quais são as formas de individualismo dentro da sociedade da insatisfação?}

Heller diz: o individualismo burguês apresenta-se como uma função particular dessa individualidade. $\mathrm{O}$ egoísmo e cinismo são as duas formas mais evidentes. $\mathrm{O}$ egoísmo ainda preserva alguns valores na concorrência comercial. O cinismo, nem mesmo leva em consideração "os regulamentos sociais que impedem os egoístas cotidianos de explorarem, até o fundo, as conseqüências de seu modo de agir - é preciso derrubar os freios que contêm os pequenos-burgueses" (1982b, p. 140).

Isso equivale a condenar, ética e politicamente, todas as formas de conduta orientadas particularisticamente? Heller responde:

(...) isso não significa que eu condene a particularidade. Digo que são moralmente mais elevados os que raciocinam e atuam como indivíduos e creio que a transformação socialista tornará possivel que todos os homens se elevem da condição de sujeitos particulares à de sujeitos individuais. Mas se eu pretendesse hoje condenar todo sujeito particular, seria uma aristocrata. Com efeito, existem estratos sociais que vivem em condições que não permitem (ou permitem apenas os sujeitos inteiramente excepcionais) transformar-se em sujeitos individuais. (1982b, p. 140)

É hora de perguntar: que moral é essa e o que a legitima? 


\subsection{Moral e indivíduo}

O direito a ser um indivíduo passa pela necessidade de vencer os particularismos. Indivíduos são os pontos máximos atingidos pela historicidade da essência humana objetivada.

When we consider the historical development of individuality, we never depart from the average individual of an age or society. We analyse the maximum possibility created in a given period for the development of individuality. Maximum possibilities can be deciphered from representative individuals, those exceptional personalities who completely realize their potencialities within the historical context. (Heller, 1973b, p. 16)

Indivíduos são, portanto, o máximo de desenvolvimento da essência humana ou das individualidades. Quanto maior o grau de alienação social, menor será o desenvolvimento das individualidades - o homem médio será a pessoa particularista.

Particularidade e individualidade não são, entretanto, categorias descritivas da realidade humana - são, sem dúvida, juízos de valor. Ser um homem individual é melhor do que ser uma pessoa particularista. São tipos ideais ou valores por meio dos quais julgamos o desenvolvimento das individualidades.

Certamente, todo homem é resultante de um processo de individuação e possuidor de uma individualidade. O desenvolvimento dessa individualidade em direção ao tipo ideal, "homem individual", é positivo, porque resulta de um maior desdobramento de potencialidades humanas. O desenvolvimento em direção ao tipo "pessoa particularista" resulta de uma alienação das possibilidades humanas, ou pela extinção de algumas de suas necessidades ou pela unilateralidade delas.

Todos nós somos, portanto, individualidades. Nosso agir moral é que nos qualifica como indivíduos ou pessoas particularistas. Mas, em relação ao que nosso agir é julgado? Diz Heller:

Morals can best be described as an individual's pratical relationship to the norms and rules conduct. Two aspects of this relationship can this be distinguished: the individual's relationship on the one hand, and the norms and rules of proper conduct to which the individual relates himself or herself on the other. Using Hegelian categories we would term the first aspect 'morality' and the second aspect 'Sittlichkeit' (collective moral habits, norms and prescriptions). (1988, p. 75)

Heller tem a sua própria ética - uma ética socialista, que defende a socialização da natureza humana enunciada pelo jovem Marx e que tem pontos em comum com a "segunda ética kantiana"(Metafísica da ética e A religião dentro dos limites da razão pura) (1984b). Tem como hipótese a aceitação de três deveres ou normas para uma ética socialista: a norma do hábito das discussões racionais; a norma do reconhecimento dos carecimentos dos outros, com exceção da exploração e da dominação (que convertem outras pessoas em meros instrumentos) e a norma do desenvolvimento de nossas capacidades. Qualquer transformação passará pela transformação das individualidades - obviamente, a meta é o 
desenvolvimento da individualidade em direção ao homem individual, que realiza em si a síntese espécie-indivíduo. Como, é outra questão.

Colocamos como problema de pesquisa a fetichização total do capitalismo, cujo índice perfeito seria a ausência do sujeito propulsor de transformação social. Diz Heller:

Não pretendo absolutamente negar que, nas modernas sociedades industriais, a alienação da personalidade tornou-se um problema decisivo e que pode tornar-se a fonte de uma violência irracional. (1982b, p. 34)

$\mathrm{Na}$ perspectiva da dialética negativa de Adorno, é inócua a pretensão a mudanças sociais profundas, o que torna irrelevante qualquer discurso sobre o homem individual e a sua ética rigorosa. Mas definitivamente Heller é contránia às lamentações e ao desespero de Adorno:

Adorno's attitude is anything but frivolous. And yet, it seems to us that there is some wavering within the formulation of that attitude. In fact, its point of departure, according to which Marxist philosophy is seen to have missed its moment of realization, is already frivolous... What gives the philosopher the power to determine the moment when theory was to be realized or, conversely, the moment when theory failed to be realized? (1977, p. 134)

Não é que as mudanças sociais não sejam possíveis - são as teorias da revolução que precisam perder o caráter jacobinista, em virtude da experiência histórica e das práticas políticas catastróficas. Bem como o próprio conceito de socialismo. "To ask what socialism means is primarily a question of goals and or redefining values such as equality, freedom or brotherhood. In addition to certain desirable values, there is equally a need to identify negative values such as repression and to strive toward making these obsolete. We could not criticize or reject any type of realized socialism if we do not see socialism as a value' (Heller, 1978, p. 153).

Heller propõe a mudança de modos de vida com a da formação de novas comunidades, livremente escolhidas, como a precondição para uma sociedade realmente socialista. E o antídoto ao individualismo e às pessoas particularistas.

A práxis é um processo de desenvolvimento e isso pressupõe novos tipos de esfera pública, novos níveis de discussão e instituições. Para mudar o caráter moral dos seres humanos são necessárias novas instituições, comunicação racional e comunidades.

Rational communication brings individuals into a situation which obliges them to thinkabout their particularity: the living community obliges them to act with a view toward transcending their particularity. Institutions that foster thinking with and for one another can further the elimination of greed and the ambition to dominate. Not by human goodness alone, but through institutions can people and society change. (Heller, 1978, p. 153)

Revolução não pode ser "golpe de Estado", mas alteração dos estilos de vida por meio da interação humana, guiada pelos princípios democráticos. Lenta, gradual e molecular, ela consistirá sobretudo, de uma radicalização da democracia ao nível das relações sociais e humanas. 


\subsection{O cotidiano e os processos de desenvolvimento das individualidades}

Os conceitos de "indivíduo" e "pessoa particularista" nos remetem a uma distinção kantiana entre o homo noumenon e o homo fenomenon, ou seja, entre a idéia, não fundada empiricamente, de humanidade como deveria ser e a idéia fundada empiricamente de humanidade existente. São dois conceitos de espécie humana em que o primeiro serve de idéia reguladora das ações humanas inseridas no mundo causal, temporal e fenomênico. Diz Heller que 'también Marx confronta em los Manuscritos-Econômico-Filosóficos la descripción del hombre alienado del presente y la idéia de una humanidade no alienada. Esta cumple, sin duda, la función de una idea reguladora - ha de dingir nuestros actos y debemos aspirar a su realización' (1984b, p. 27).

O problema é que Kant põe entre parênteses a gênese do conceito empírico de humanidade e da idéia valorativa desta.

A Kant le es completamente ajena la idea, evidente para nosotros, pero también para muchos de sus contemporáneos, según la cual en la aparición y la permanencia pero aún más en la eficácia de la idea de la humanidad el papel dominante lo han jugado las necesidades de la humanidad existente - aunque ésta es una idéa que no se corresponde com la existencia empírica (en otro caso no seria una idea) - que determinadas necessidades de la humanidad existente son la fuente de esa idea que contrapone el hombre a la existencia. De este razonamiento se sigue que la inclinación y la necessidad pueden ser portadoras de la idea de la humanidad, si bien no bajo la forma de una idea, sino como su fuente. (Heller, 1984b, p. 29)

Prisioneira de seu tempo, a pessoa particularista é um índice seguro de alienação da espécie; por outro lado, o indivíduo é, desde já, o novo homem forjado no presente, mas cujo comportamento ético-político é orientado por necessidades radicais de transcendência. Embora não sejam propriamente categorias descritivas do real, "indivíduo" e "pessoa particularista" são conceitos teóricos fundados nas análises histórica, antropológica e por que não psicológica das tendências e necessidades do homem contemporâneo. Isso nos conduz ao plano do cotidiano, meio no qual (e pelo qual) os homens desenvolvem a sua existência social como pessoas.

O homem nasce num mundo já constituído, no qual deve aprender a viver. Aprender a usar as coisas, adquirir os costumes e normas de conduta, bem como atender às demandas sociais, constituem condições para a sua reprodução como ser individual e social. Em outras palavras, deve adquirir "competência social", pelo menos num certo grau, face ao sistema de objetos, hábitos e instituições (Heller, 1984c, p. 4).

Mas há, sem dúvida, cotidianos e cotidianos. Microesferas sociais da atividade humana individual, os cotidianos apresentam total heterogeneidade. Heller propõe, para interpretar o cotidiano como conceito filosófico (que Marx apresentou como uma esfera de alienação da essência humana), um conjunto de conceitos e categorias.

Diz: Everyday life is objectification (1984c, p. 117), ou seja, é o processo por meio do qual se dá a externalização do sujeito, a ação do sujeito no mundo que o cerca. Mas não toda objetificação é relacionada a uma objetivação. 
First and foremost, all objetivations are species-essential, in that they incorporate various types of species essentiality. Second, they are not simply the consequences of externalized, objetivized activity, but referential orders which are external in relation to the activities of the persons who activate them while appropriating them. (1984c, p. 117)

Esclarecemos: subir uma escada é uma atividade que pertence, sem dúvida, ao cotidiano de qualquer um, mas não é atividade objetivadora, embora seja uma externalização. Há ainda outras atividades que nem mesmo podem ser consideradas como "objetificação": impulsos, motivações casuais não traduzidas em ação, sonhos etc. (1984c, p. 117).

Para compreender a natureza específica das objetivações, Heller usa a distinção ser-em-si-mesmo (being-in-itself) e ser-para-nós (being-for-itself), dizendo que:

In relation to nature, being in itself is anything the has not yetbeen pervaded by praxis and cognition; and in so far - if we are dealing with the relationship between nature and society - we can regard the whole realm of praxis as being for itself. (1984c, p.117)

Os constituintes da primeira esfera são os instrumentos e os produtos, os costumes e a linguagem. Obviamente, o ingresso do indivíduo na vida social se faz por essa esfera, já constituída antes de sua existência. Mas terá condições de tomar consciência de si mesmo enquanto espécie humana através da mera socialização que decorre da apropriação das normas e costumes, bem como das regras de uso dos instrumentos de trabalho? Provavelmente, não. Embora objetivações da espécie, esses produtos culturais pertencem à esfera da necessidade e não da práxis.

No entanto, não se pode dizer que esta esfera seja, por isso, uma esfera de alienação e puramente adaptativa. Heller discute a posição de Heidegger a respeito do caráter "inautêntico" das ações orientadas nessa esfera do cotidiano. O fato de nos tornarmos pragmáticos e eficientes no agir cotidiano não nos obriga a uma perda da consciência de nossa essência genérica nem tampouco a aderir cinicamente aos particularismos. Mas se as relações sociais estão alienadas, o nosso cotidiano pode se inclinar para a alienação (1984c, p. 256-257).

A segunda esfera é constituída por objetivações culturais tais como a filosofia, as artes, as ciências e as religiões. Diríamos que foram criadas como mediações para o homem ver a si mesmo como espécie humana. Por isso, não são componentes necessánios da socialidade - muitas estruturas sociais funcionaram sem tais objetivações. A filosofia, por exemplo, era um componente da polis ateniense, mas Esparta e outras cidades-estado podiam funcionar socialmente sem a produção filosófica. No capitalismo avançado, as ciências naturais são um componente necessário (1984c, p. 119).

No entanto, embora permita o auto-reconhecimento do espírito humano, porque foi criada com essa intencionalidade, a esfera da objetivação, para-si-mesma não é sinônima de não alienação, da mesma maneira que a outra não é sinônima de alienação: a ciência pode ser alienada, enquanto a linguagem pode se tornar um meio básico para toda a atividade humana para-si-mesma (1984c, p. 120). 
A terceira esfera de objetivações constitutivas do cotidiano são as estruturas políticas, as instituições e as leis. Heller chama de objetivações em-si-mesmas-e-parasi-mesmas.

É claro que tais distinções não implicam separação das várias esferas: como é que se pode conceber a religião, por exemplo, sem a instituição religiosa? Ou sem a linguagem? Na verdade, a última esfera é a de estrutura da sociedade na qual as instituições constituem subsistemas.

A esfera que exerce uma função crítica das outras esferas, embora não necessariamente de forma explícita, é a das objetivações para-si-mesmas.

But no science can morally legitimate the social differences between skills and the social manners which have to be apropriated; in particular, no science can contend that there exists a legitimate necessity for these social difference. Furthermore, no science can legitimate the sexual division of labour, especially not a necessity for it. Consequently, all those who experience class, sex and race discrimination will perceive the division of the objectivation in itself as unjust or at least they will tend to do so. (Heller, 1985, p. 137-138)

Isso não quer dizer que a ciência não possa ser também legitimadora da estrutura social existente.

O processo de apropriação da objetivação em-si-mesma é, simultaneamente, um processo de subjetivação e objetivação. Como resultado, o produto é simplesmente uma versão, mais ou menos perfeita, da espécie humana - ele é um sujeito com a consciência de sua própria subjetividade, de ser um Eu particular. Este sujeito não é o resíduo de um processo de socialização nunca completo, mas é a força da própria socialização. Embora se apropriem das mesmas normas e regras, os sujeitos humanos não se tornam uniformes (1985, p. 84-85). Ou seja, o processo de socialização (que é a apropriação do mundo objetivo) é um processo de individuação ou singularização.

É preciso verificar, agora, como é que a alienação atua na formação das subjetividades individuais. Embora não de forma exclusiva, é o domínio das objetivações em-si-mesmas que favorece a alienação consciencial, na medida em que restringe o cotidiano a uma adaptação do sujeito às normas e regras de uso dos objetos e instrumentos de trabalho. Diz Heller:

We know that the development of the personality is the process of objectivization into subjectum. And in the light of what we have said, we may now venture upon the assumption the personality is objectivized into subjectum 'in itself' status in the particulanistic person: while, in the individual the personality is objectivized into subjectum 'For itself'. (1984c, p. 121)

Há, portanto, duplo processo de individuação (ou dois estágios do mesmo processo), sempre resultando num objeto que é o próprio sujeito. Quando o sujeito não vê a si mesmo como uma singularização do outro genérico, que é a sua essência humana, temos o modo de ser particularista. Daí a racionalização do egoísmo ou do mais genuíno cinismo que justifica as necessidades anti-societárias de explorar ou dominar o outro visto como mera externalidade. O contrário sucede com o indivíduo: 
ele mesmo, como individualidade ou diferença, é mediação para conhecer o outro como si-mesmo.

A alienação tem, portanto, a sua expressão subjetiva na pessoa particularista. Retomaremos a mesma questão, agora, do ângulo das necessidades, isto é, 'from that of need-creation, need-perception, need-distribution and need-satisfaction' (Heller, 1988, p. 14).

\section{Necessidade e individuação}

Parece que a problemática do indivíduo e da subjetividade surge, no marxismo ocidental, quando a classe proletária toma férias de sua missão histórica... Nasce a Psicologia Política quando as "forças objetivas" da história não encontram o seu suporte ou mediação política e a contradição dialética do todo morre na praia. Daí, surge a pergunta sobre "forças subjetivas", aquelas não muito visíveis mas cujo poder parece difícil de negar. Até mesmo porque, muitas vezes, elas são contra-revolucionárias. A personalidade autonitána (Adorno, 1965) tentou romper com o véu da invisibilidade dessas "forças subjetivas", que, no entanto, são capazes de decidir a História. Buscar o substrato psicológico do fascismo ou detectar os componentes inconscientes e irracionais do comportamento etnocêntrico são maneiras de reativar a força revolucionária da teoria marxista, aguçando os instrumentos de análise da realidade que precisa ser transcendida. Estamos a falar, sem dúvida alguma, dos freudo-marxismos.

Terá a obra de Heller atendido à mesma demanda explicativa? É prematuro responder, mas parece que Heller se preocupou sobretudo com a reedição do Jacobinismo nas revoluções ditas socialistas do Leste Europeu, e as ditaduras resultantes (1982a). Sem abandonar uma perspectiva socialista, ela recuou ao jovem Marx, ao Marx dos carecimentos radicais, para entender por onde passa um verdadeiro processo revolucionánio. Não há teoria revolucionánia, por mais crítica e radical que seja, que possa se converter numa força material se não se encontrar com necessidades radicais, produzidas social e historicamente (1973a). Isso equivale a dar um peso maior ao subjetivo na História, pois é no sujeito individual que os carecimentos têm moradia.

\subsection{A teoria das necessidades de Marx}

Vamos apresentar a teoria das necessidades de Marx, de acordo com as leituras ou interpretações de Agnes Heller (1976) e Patrícia Springborg (1983).

A obra de Heller foi publicada, pela primeira vez, em tradução italiana de seus manuscritos em húngaro, em 1974. Em inglês, surgiu em 1976. O livro de Springborg 
é da década de 1980, o que permite ver a histónia do conceito e o debate contemporâneo sobre as necessidades.

\subsubsection{Valor de uso e necessidade}

A primeira definição de mercadoria como valor-de-uso n' O Capital nos remete imediatamente à necessidade. Estamos na esfera da circulação das mercadorias onde elas são desejáveis como valores-de-uso e em que o ciclo de vida de cada uma termina no consumo (embora o valor continue a circular na forma de dinheiro). Diz Marx que uma mercadoria é uma coisa que, pelas suas propriedades, satisfaz necessidades humanas do estômago ou da fantasia (1980, p. 41).

Além da necessidade figurar, de modo essencial, na definição do valor-de-uso, fica explícita a sua participação na engrenagem econômica, que não se limita à esfera do consumo. Para continuar produzindo novas mercadorias, é necessário criar novos carecimentos. Os valores-de-uso são para satisfazer necessidades humanas. Nesse sentido, as necessidades são imprescindíveis para a existência de valores-de-uso e para a produção econômica, de modo geral. Podemos pensar em formas de produção econômica nas quais os valores-de-uso não apareçam sob a forma de mercadorias (ou valores-de-troca), mas não podemos pensar numa economia que não seja criada para atender às necessidades humanas.

É obvio que o fato dos valores-de-uso aparecerem na forma de valor-de-troca, sob o capital, altera historicamente as necessidades humanas, assim como altera a forma de produção e do consumo. Trata-se de um "sistema de necessidades" específico do capital. Expliquemos por quê.

A realização do valor da mercadoria se faz através de compra e venda. Após a realização do valor é que a realização do valor-de-uso ou o consumo da mercadoria se faz possível. Daí, então, que a principal necessidade é a necessidade de ter, porque valor só se realiza mediante valor. Dá para entrar num supermercado sem dinheiro?

Em outras palavras, o próprio sistema econômico vai organizando as necessidades de que tem necessidade para a valorização crescente do valor. Isso que dizer que todas as necessidades são socialmente determinadas? Não há necessidades naturais?

\subsubsection{A classificação das necessidades}

Embora necessidade defina valor-de-uso, Marx não descreve o que é entendido pelo termo necessidade (Heller 1976, p. 23). Por quê? Heller diz:

Now is should no longer appear to be an accident that the concept of need plays the hidden but principal role in Marx's economic categonies, just as it is no accident that the concept of need is not defined in his critiques of political economy and capitalism. Marx's categonies of need are not, as a whole, economic categonies. He tends to treat concepts of needs as non-economic 
categonies, as historical-philosophical, that is as antropological value categonies, and therefore as not subject to definition within the economic system. (1976, 19, p. 27)

Dado que o conceito de necessidade não é econômico, mas também econômico, as classificações marxianas das necessidades vão depender do ponto de vista adotado: antropológico, histórico-filosófico ou econômico.

Segundo a interpretação de Heller, quando Marx classifica as necessidades como "naturais" e "socialmente produzidas", não está negando conteúdo social às chamadas necessidades naturais. As necessidades de alimento, vestimenta, moradia são naturais ou físicas porque, sem atendê-las, perde-se a condição de sobrevivência física. São, portanto, "necessidades necessárias". Mas têm um caráter socialmente produzido porque o modo de satisfazê-las é social: o modo ocidental de satisfazer a fome com a ajuda de faca e garfo, por exemplo.

Heller conclui:

In our view the natural needs are not a group of needs but a limit concept: a limit (different for different societies) beyond which human life is no longer reproducible as such, beyond which the limit of bare existence is passed (mass deaths from famine in India an Pakistan show exactly this)... Therefore I shall speak not of 'natural needs' but of the existential limit to the satisfaction of needs. (1976, p. 32-33)

Será, portanto, que no pólo de oposição às "necessidades necessárias" vamos encontrar "necessidades supérfluas" ou de coisas supérfluas (como dizemos, que não são de primeira necessidade)?

Heller discute o estatuto das luxury needs nos textos de Marx. Não há dúvida que o desenvolvimento extraordinário das forças produtivas sob o capital requer uma expansão quantitativa e qualitativa do consumo. Isso implica uma propagação das necessidades existentes num círculo mais amplo e a produção de novas necessidades através da descoberta e criação de novos valores-de-uso.

Qual é o critério implícito para distinguir "necessidades necessárias" de "necessidades de luxo"? Diz Heller que a categoria de luxury needs só pode ser interpretada num sentido econômico e relativo. Uma "necessidade de luxo" pode se converter numa "necessidade necessária" como conseqüência da produtividade crescente e como conseqüência de alterações na estrutura social. Na verdade, as "necessidades de luxo" são aquelas que não pertencem ao sistema de necessidades da força de trabalho: um objeto é "de luxo" se não está ao alcance do poder aquisitivo da classe trabalhadora. Esta oposição é, portanto, não só relativa, mas superável numa sociedade de "produtores associados".

Em última análise, portanto, todas as necessidades, quer naturais ou necessárias, quer socialmente produzidas, quer luxury needs, são necessidades sociais. Mas o conceito de "necessidades sociais" tem vários sentidos em Marx, segundo a exegese de Heller.

O primeiro e mais importante sentido de necessidades sociais é o de necessidades socialmente produzidas, que são as necessidades dos seres humanos individuais. Em 
alguns lugares, essa classificação inclui apenas aquelas que não são necessidades naturais; em outros lugares, inclui todas as necessidades indiscriminadamente (1976, p. 69).

Nesse sentido, "social" é determinante categorial da necessidade, mas não é juízo de valor. Num outro sentido, "social" traz conotação valorativa: é necessidade social a necessidade que o homem tem de comunismo, do homem socializado, e não brutalizado pelas forças econômicas. 'Here, therefore, social need means the needs of socially developed humanity. It is unnecessary to emphasize that here, too, social need means the need of the individual human being' (1976, p. 70).

Outro sentido corresponde ao de demanda efetiva por bens materiais numa sociedade ou classe (p. 71-72). Vale, pois, num sentido econômico.

Mas há um quarto sentido de necessidades sociais que são aquelas que só podem ser satisfeitas através da criação de instituições sociais ou da vida comunitária, como as necessidades de saúde e educação (p. 72-73).

As classificações deixam transparecer, de um modo ou de outro, o caráter societário das nossas necessidades, quer "individuais", quer "sociais", quer "naturais" etc. É impossível separar necessidades humanas de vida societária e, portanto, do processo histórico. É o que as classificações estão a refletir, sendo elas mesmas históricas. Daqui a pouco, o quadro classificatório bem poderá ser outro.

\subsubsection{Necessidades sob o capital}

A historicidade do "sistema de necessidades" engendrado pela alienação econômica do capital permite a previsão de sua caducidade e transcendência. Se se vive num regime econômico que exige a expropriação da força de trabalho pelo capital, então o próprio sistema, através das relações sociais e humanas, está a produzir o aparecimento de um certo tipo de necessidade: a necessidade de libertação de tal processo alienador. Obviamente, as relações sociais mediadoras produzem tal necessidade, mas não satisfazem. Eis o começo do fim do capitalismo: a emergência de necessidades radicais, membros efetivos e incômodos dessa formação.

It is not the Being of radical needs that transcends capitalism but their satisfaction. Those individuals for whom the radical needs already arise in capitalism are the bearers of the 'Collective ought'. (Heller, 1976, p. 77)

Necessidades radicais são, pois, socialmente produzidas mas não poderão ser socialmente satisfeitas, a não ser com a transcendência do existente. Em outras palavras, é a necessidade da revolução socialista, ou a "necessidade de universalidade", que encontra na classe trabalhadora o seu sujeito coletivo (1976, p. 85-86). É a condição subjetiva do processo revolucionário, determinada objetivamente pelas próprias forças em expansão do capital.

Poderíamos, então, julgar que a necesidade de transcendência da alienação econômica é boa, enquanto a necessidade de acumular bens ou a necessidade de 
consumir o-que-apareça-pela-frente não são tão boas assim... Ou seja, poderíamos julgar algumas necessidades como alienadas e outras, como não-alienadas.

Heller adverte: 'From the philosophical point of view, individual concret needs cannot be analysed in isolation, since neither isolated needs nor isolated types of need exist' (1976, p. 96). Toda sociedade organiza as necessidades humanas de acordo com uma determinada estrutura, formando um sistema de necessidades específico a essa sociedade. A estrutura de necessidades sob o capital subordina todas as necessidades à necessidade de posse. O impacto da alienação econômica capitalista sobre as necessidades humanas provoca pelo menos 4 grupos de problemas:

1. a inversão na relação meios-fins;

2. a quantificação das necessidades, em detrimento da qualidade;

3. redução e homogeneização das necessidades;

4. redução das necessidades ao interesse.

Parte-se do pressuposto que a finalidade da produção econômica é a satisfação das necessidades humanas. Mas quando a produção é eminentemente mercantil, não só ela domina qualquer esfera produtiva para qual ela produza valores na forma de valores-de-troca, como a própria necessidade passa a ser um meio para gerar mais valor, que se torna a finalidade real. Diz Heller que 'it is not going too far to say that Marx actually discovered the problem of manipulated needs and indeed of the manipulation of needs' (1976, p. 51). É a inversão meios-fins.

A pressão econômica estimula a necessidade quantitativa de acumular bens ou buscar prioritariamente valores, assim como inibe necessidades meramente qualitativas:

The person who deals in diamonds, as Marx writes, pays no attention to the aesthetic beauty of the diamond, because he sees it only as an embodiment of exchange value. True wealth is on the contrary, the development of heterogeneous qualities in types of needs. (1976, p. 52)

O sistema capitalista de necessidades por excelência se integra à estrutura da produção pela da categoria do interesse. Não foi por acaso que as teorias econômicas burguesas elegeram o interesse como categoria motivacional, porque é esse conceito que define estruturalmente o sistema de necessidades sob o capital. O interesse é a expressão do egoísmo individual em eterno confronto com os outros egoísmos no mercado competitivo. Nada mais equivocado, portanto, do que identificar "interesses de classe" com "necessidades radicais". Motivações dessa ordem são sempre particularistas e afetadas pela alienação econômica.

Não parece haver dúvidas quanto ao fantástico e incomparável poder do capital de engendrar riquezas ou a competência da burguesia em promover uma organização social do trabalho capaz de administrar o vigor das forças produtivas postas em movimento. O problema reside na autonomia do processo econômico em relação ao sujeito humano, origem e alvo dessa produção, mas que passa a servir à incoercível 
necessidade de crescer do capital. É a irracionalidade da racionalidade capitalista que produz riqueza social à custa do empobrecimento das necessidades individuais.

A meta histórica é o homem "rico em necessidades", a reconquista da liberdade de não ser mero instrumento da economia. Daí, então, a riqueza será gozo e oxigênio para o espírito humano.

\subsection{Heller: uma visão contemporânea da teoria das necessidades}

Em maio 1978, houve um importante encontro científico em Berlim, promovido pelo International Institute for Environment and Society (Science Center Berlin) em cooperação com a United Nations University, para avaliar o state of art na pesquisa sobre necessidades humanas corno base para formular políticas ambientais no mundo (Lederer, 1980). Heller teve um papel relevante na discussão teórica sobre as implicações normativas e políticas dos conceitos de necessidade. Tomaremos o seu artigo como base para a apresentação de sua visão das necessidades na atualidade.

\subsubsection{Necessidades verdadeiras e necessidades falsas}

Aparentemente inocente, a distinção verdadeiro/falso no terreno das necessidades tem implicações até perigosas no plano político. Bem como no ético. Por isso, é uma questão polêmica diante da qual Agnes Heller se posicionou com veemência, procurando explicitar os seus pressupostos ontológicos, bem como as implicações ético-políticas (1980).

Essa questão oferece, na minha opinião, uma grande oportunidade para compreender a visão que Heller tem das necessidades humanas, a partir e para além da teoria marxiana.

Marx talvez tenha sido o primeiro filósofo a perceber a instrumentalização das necessidades humanas na sua forma manipulativa: a heteronomia dos desejos e dos interesses representa a degradação da necessidade humana convertida em meio. Fetichizada pela alienação econômica, ela se converte em aparência com o próprio mundo aparencial e encantatório das mercadorias. Daí se pensar em necessidades falsas. Disse Marcuse:

A maioria das necessidades comuns de descansar, distrair-se, comportar-se e consumir de acordo com os anúncios comerciais, amar e odiar o que os outros amam e odeiam, pertence a essa categoria de falsas necessidades. Tais necessidades têm um conteúdo e uma função sociais determinados por forças externas sobre as quais o indivíduo não tem controle algum: o desenvolvimento e a satisfação dessas necessidades são heterônomos. (1979, p. 26) 
Marcuse está se referindo a um tipo de manipulação sutil, via propaganda ou anúncio comerciais, que funcionam como controles sociais não-aversivos, que não geram reações ou contracontroles do sujeito-alvo.

O resultado do controle positivo e da satisfação da necessidade manipulada é a "euforia na infelicidade" - o pior tipo de alienação consciencial. Tomemos, por exemplo, o estímulo recebido por milhares de brasileiros pobres para jogar na loteria esportiva, enorme fonte de arrecadação de dinheiro do Governo. Brasileiros respondem ao estímulo e gostam de fazê-lo, sem perceber que estão praticamente pagando mais um imposto ao Governo.

\section{Continua Marcuse:}

As únicas necessidades que têm direito indiscutivel à satisfação são as necessidades vitais de alimento, roupa e teto ao nível alcançável de cultura. O atendimento a essas necessidades é o requisito para a realização de todas as necessidades, tanto das sublimadas como das não-sublimadas. (1979, p. 27)

A posição de Heller é muito clara a esse respeito. Sem negar a instrumentalização das necessidades sob o capital, ela julga que o conceito de alienação só é aplicável à totalidade da estrutura das necessidades numa dada sociedade, e não a um grupo específico de necessidades consideradas "falsas" ou "ilusórias".

A qualificação verdadeiro/falso padece de uma deficiência teórica: ela coloca o que julga (o teórico) fora do mundo a ser julgado, na posição de 'a god passing judgement upon the system of needs of society' (1980, p. 215). Além disso, há um perigo prático nessa distinção, se aquele que julga não é um teórico, mas um conjunto de instituições sociais que se arroga o direito de distinguir necessidades reais de imaginánias. A ditadura sobre as necessidades humanas ganha, com isso, uma boa justificativa para oprimir aspirações ou para não produzir os objetos que satisfaçam as necessidades consideradas falsas. É a guilhotina do Estado aplicada contra a multiplicidade e diferenciação das necessidades humanas, tão negativa quanto a crescente instrumentalização dos carecimentos promovida pelo capital em expansão. É o que Lukács denominou de "manipulação brutal" (1980, p. 222).

Poderíamos, então, concluir que todas as necessidades são boas e devem ser satisfeitas? Ou então, que algumas são boas e outras são más? Poderão as necessidades ser julgadas de um ponto de vista ético?

A questão do juízo moral sobre necessidades acarreta as mesmas dificuldades já mencionadas anteriormente: quem julga o que e com que direito? É supor que aquele que julga é o único ser dotado de boa consciência... Além disso, a variedade das culturas e das normas torna impraticável qualquer tentativa de universalizar os juízos morais.

No entanto, diz Heller, há algumas necessidades cuja satisfação implica que outras necessidades de outras pessoas não possam ser atendidas. São as necessidades, mencionadas por Kant, que pressupõem o uso de outras pessoas como instrumentos. São as necessidades de posse, dominação e ambição. Na medida em que são 
necessidades cuja satisfação é equivalente à frustração das necessidades das pessoas instrumentalizadas, então não são boas necessidades. Diz Heller, conclusivamente: "The categonal imperative has, therefore, a restrictive function in the assessment of needs' (1980, p. 218).

\subsubsection{Necessidades radicais e modernidade capitalista}

Heller diz que a estrutura das necessidades do mundo ocidental moderno difere especificamente da estrutura das necessidades em sociedades pré-capitalistas (1985, p. 300). Estará atribuindo aos determinantes econômicos a responsabilidade imediata (ou mediatizada) por aquilo que sentimos como "nossas necessidades? À primeira vista, pode parecer que sim. Mas, na verdade, não há nenhum economicismo na análise helleriana das necessidades.

A teoria que desenvolveu sobre as objetivações constitutivas da categoria "cotidiano" revela que o modelador principal das nossas necessidades, capaz de organizá-las num sistema, é o conjunto dos valores que permeiam a cultura, a tradição e os costumes.

A modernidade capitalista, diz, se caracteriza por valores ou sistemas valorativos advindos do desenvolvimento de três tendências simultâneas, que acabam conflitando entre si: a industrialização, a capitalização e democratização. Por elas, nossas expectativas e anseios de liberdade, progresso econômico, bem-estar social, alívio de sofrimento, justiça social, liberação do trabalho forçado, desenvolvimento das individualidades etc. parecem próximas da verdade. No entanto, a lógica da capitalização crescente não combina muito com os valores democráticos: de onde se extrai valor? É possível a equalização democrática quando o capital em expansão reproduz desigualdades sociais?

Everyone who takes seriously the values of freedom, equality and alleviation of suffering in regard to humankind as a whole, will judge consumerism in a tiny part of the world to be an outrage against those who die in famine, suffer from regular malnutrition on an earth we share. How can we proudly assert: 'I am a human being', if we do not care for human beings?

And when asking this question, one should be aware of the fact that the general dissatisfaction which includes all protests against suffering, humiliation, oppression and domination is the offspring of the same culture, of the same value system, of the same progress which it criticizes, rejects and tries to overcome. Dissatisfaction with dissatisfied society belongs to that same society. (1985, p. 310)

Em outras palavras, a sociedade capitalista engendra a compulsão para o consumo, ao lado da necessidade por uma democracia realmente justa, mas é óbvio que a primeira encontra mais satisfação que a segunda. Ou seja, ela cria muitas necessidades democráticas, mas não os satisfiers - os impulsos e as aspirações tendem a ser reprimidos, então, pela mesma tendência que os fomenta. Essa espécie de 
"demanda reprimida" por uma democracia verdadeira é o que, desde Marx, se denomina de necessidade radical.

A diferença entre necessidades radicais e não-radicais está em que as primeiras 'come about via reflection on universalistic values where as other needs are only shaped by the latter without reflection on universalistic values. Reflection on universalistic values can provide people, if not with a way of life, at least with a conduct of life' (1985, p. 311). Lembremos aqui que uma das esferas das objetivações culturais que Heller chamou de "para-si-mesma" é a que mais propicia elementos para a reflexão sobre os valores universais e para a crítica do cotidiano meramente alienado, sobretudo na esfera das objetivações em-si-mesmas. Isso não quer dizer que indivíduos conscientes não desejem tomar uma Coca-Cola ou que vivam isolados da maioria - o seu modo de agir é que sofre alterações éticas e políticas por força das necessidades radicais.

Cabe, agora, a questão se todas as necessidades engendradas, mas não satisfazíveis na sociedade moderna, são radicais por definição? Há insatisfação e insatisfações numa sociedade que abre tanto os horizontes para o desejar humano...

Diz a filósofa:

Modern man is indeed the Faustian man; yet he does not implore the present moment to stay unchanged as it is so beautiful. Nothing should remain as it has been... We are always dissatisfied with our lot because we compare it with the unlimited possibilities beyond our reach in fact but not in imagination. (1985, p. 304)

No entanto, nada há de ameaçador na falta de limites dos desejos insatisfeitos - eles têm muito a ver com a lógica do capital e com os valores que ele engendra. É o que poderíamos chamar de insatisfação conformista.

As necessidades verdadeiramente radicais emergem da própria contradição no sistema de valores advindo do desenvolvimento da industrialização e capitalização, de um lado, e da radicalização democrática, de outro. Não se trata de buscar uma sociedade conformista, mas de alcançar a resolução do conflito, que encarna a contradição entre interesses individualistas e necessidades sociais, no sentido pleno da expressão. Quando os ecologistas lutam politicamente pela preservação da Natureza para resguardar as condições de vida da espécie humana, não são encarados como poetas românticos e delirantes, mas ameaças vivas ao setor produtivo e aos interesses em ação. Veja-se o exemplo de Chico Mendes...

Na visão de Marx, o corpo social do capitalismo engendra não só as necessidades radicais, as "necessidades de universalidade" e de transcendência da alienação existente, como também os próprios portadores das necessidades radicais. Porque, em Marx, as personalidades individuais não são os determinantes das necessidades, mas sim, a posição do sujeito na divisão social do trabalho. Nesse sentido, os portadores das necessidades radicais são os trabalhadores. A eles cabe a conquista do poder do Estado e a eliminação da divisão do trabalho sob o capital. 
Não há dúvida que as necessidades radicais, em Marx, podem ser traduzidas como "a consciência da alienação da espécie humana" e que a posição do proletariado na ordem social/capitalista determina essa consciência, que não se limita à consciência empírica de sua própria miséria e sofrimento.

A teoria das necessidades radicais de Agnes Heller não tem essa implicação. Diz:

(...)os carecimentosradicais estão presentes e, portanto, o futuro é deduzidoa partir de realidades existentes. Ao mesmo tempo, porém, (a minha teoria) recusa a construção filosófica do sujeito revolucionário. Com efeito, a teoria nos diz apenas que todos os estratos sociais que expressam carecimentos radicais podem tomar-se sujeitos da transformação revolucionária. (1982b, p. 133)

Em vez de buscar explicações psicanalíticas para o comportamento político da classe trabalhadora, quando ela se recusa a comandar um processo revolucionário, Heller prefere analisar a tese marxiana como mera construção filosófica do sujeito revolucionário. Do ponto de vista da práxis, portanto, a teoria helleriana dos carecimentos radicais é absolutamente aberta: o agente de transformação não é predeterminado por teoria alguma. É preciso, isso sim, analisar no concreto existente os sinais de emergência de necessidades radicais como precondições para mudanças sociais e otimizá-las conscientemente.

\section{Conclusões}

Apesar das dificuldades mais que previsíveis, estivemos a imaginar como estudar um "sistema de necessidades", do ponto de vista científico. Não há dúvida que se trata de uma construção filosófica, meramente teórica, inspirada em Marx. Mas não será possível, por exemplo, lhe dar uma dimensão ou um "significado psicológico" através da pesquisa empírica?

Desejar, aspirar, ter motivação para, querer determinadas coisas e rejeitar outras, não serão expressões individualizadas de algum sistema (oculto) coletivo de necessidades? Será que esse não é o pressuposto das próprias pesquisas de mercado que acabam programando o perfil do produto de acordo com algum tipo de demanda coletiva expressa nas opiniões particulares? Recentemente, a Kibon alterou a propaganda de sorvetes realçando as suas propriedades nutritivas (em vez da sedução pelo sabor, cores e formas, dirigida às crianças) porque descobriu, através de pesquisa de alguns prestimosos psicólogos sociais, que as mães das crianças estavam a demandar por isso. A necessidade é, pois, a chave do negócio.

O Simpósio Internacional sobre as necessidades humanas, em 1978 (Berlim) revelou que não é fácil atacar a questão pela metodologia científica. E que a Psicologia Social está ainda muito distante do problema, de relevância social e científica 
indiscutível, porque a satisfação das necessidades está relacionada diretamente com a saúde mental e física dos homens (Klineberg, 1980).

Além da dificuldade inerente à pesquisa científica, outra ainda maior cerca o problema: uma inevitável tendência economicista nas abordagens teóricas inspiradas em Marx. As necessidades são vistas como partes constitutivas do circuito da produção, circulação ę consumo das mercadorias. Será que esta é a única ótica possível?

A teoria do cotidiano de Heller permite uma análise diferente do sistema (ou sistemas) de necessidades, num nível micrológico. Os valores que pervadem as várias esferas de objetivações constitutivas do cotidiano são os reais modeladores de necessidades. No entanto, resta saber como pesquisar essa complexa trama nas Ciências Humanas e, particularmente, na Psicologia Social.

Voltando, agora, a atenção para o problema principal desta pesquisa, temos de caracterizar com mais firmeza os pontos de vista de Heller sobre a individualidade na sociedade capitalista moderna.

Não há dúvida que Heller e os filósofos da Escola de Budapeste concentraram os esforços na análise e crítica do estatismo das sociedades do Leste Europeu, na busca de soluções políticas para a criação de uma verdadeira democracia socialista e para a eliminação da "ditadura sobre as necessidades". Mas é preciso enfatizar: sem nunca abandonar uma perspectiva socialista.

E o que é o socialismo, para Heller, senão um valor? Não deve ser entendido como categoria descritiva e sociológica de sociedades com um determinado regime de produção, mas sim, como uma necessidade, no sentido de manque e de projet. A sociedade burguesa, dissemos, liberou a individualidade para melhor dominá-la. A realização das individualidades é, portanto, uma necessidade como falta. Por outro lado, é também projeto de nossas ações políticas, mesmo quando é apenas denúncia do existente.

Ora, o que é a realização das individualidades senão o enriquecimento de nossas necessidades? O contrário, pois, da homogeneização, da tipificação redutora e da instrumentalidade dos desejos e volições. Nesse sentido, a situação de nosso "sistemas de necessidades" diz tudo: como estamos, como está a sociedade.

CARONE, I. Need and individuation. Trans/Form/Ação, São Paulo, v. 15, p. 85-111, 1992

- ABSTRACT: The modern capitalist societies critique is now mediated by the critique of the individual - the gap between psyche and culture is not maintained when a strong trend for an one-dimensional society submerges the particular into the totalitarian universal. For this reason, the knowledge of human subjectivity is not an exclusive goal of psychologists intending to penetrate into the psychical imanence. The critical philosophers have the same intention, too - and the proof are the frankfurteans' studies on authoritarianism in the 40's. Weshall introduce some aspects of Agnes Heller(1929-) philosophical work concerning about the individual's issue and the urgency of a theory of Morals that would serve as a guide for human praxis in our modern societies.

- KEYWORDS: Need; individual; ethics; praxis. 


\section{Referências bibliográficas}

ADORNO, T.W. et al. La personalidad autoritaria. Trad. Dora e Aida Combler. Buenos Aires: Proyeccion, 1965.

ADORNO, T.W. Sociology and psychology. New Left Review, London, v. 46, p. 67-81, 1967.

BENJAMIN, J. Authority and the family revisited or a world without fathers? New German Critique: an interdisciplinary journal of German Studies, Milwaukee, v. 13, p. 35-57, 1978.

FONSECA, E.G Comportamento individual: alternativas ao homem econômico. Novos Estudos Cebrap, São Paulo, v. 25, p. 151-175, 1989.

HELLER, A. The marxian theory of revolution and the revolution of everyday life. TELOS, New York, v. 6, p. 212-223, 1970.

. La teoria, la prassi e i bisogni. AUT AUT: Rivista di Filosofia e di Cultura, Florença, v. 135, p. 29-43, 1973a.

. Individual and community. Social Praxis, Mouton, The Hague, v. 1, p. 11-23, 1973b.

. The theory of need in Marx. London: Allison \& Busby, 1976.

On the new adventures of dialectic. TELOS, New York, v. 31, p. 134-142, 1977.

Marxist ethics and the future of eastern Europe. TELOS, New York, v. 38, p. 153-174, 1978.

Can true and false needs be posited? In: LEDERER, K., (ed.). Human needs: a contribution to the current debate. Massachussets: Oelgeschlager, Gunn \& Hain, 1980 . p. 213-226.

On leninism and feminism. Connexions, Oakland, Summer, n.5, p.27-31, 1982a.

. Para mudar a vida: felicidade, liberdade e democracia: entrevista a Ferdinando Adornato.

Trad. Carlos Nelson Coutinho. São Paulo: Brasiliense, 1982b.

Sobre os instintos. Trad. Ana Falcão e Luís Leitão. Lisboa: Presença, 1983.

. Aristoteles y el mundo antiquo. Trad. José Yvars e Antonio Moya. Barcelona: Peninsula, 1984a.

. La primeira y la segunda etica de Kant. In: Critica de la ilustración. Trad. G. Munoz e José L. Soria. Barcelona: Paninsula, 1984b. p. 21-96.

Everyday life. Trad G.L. Campbel. London: Routledge \& Kegan Paul, 1984c.

The power of shame. London, Boston: Routledge \& Kegan Paul, 1985.

General ethics. Oxford: Blackwell, 1987.

HELLER, A, FEHER, F. The post modem political condition. Great Britain: Polity Press, 1988.

HORKHEIMER, M. Critical theory. Trad. Matthew O'Connell et all. New York: Seaburg, 1970.

HORKHEIMER, M. O eclipse da razão. Trad. S. Uchoa Leite. Rio de Janeiro: Labor, 1976.

KLINEBERG, O. Human needs: a social psychological approach. In: LEDERER, K. Human needs. Massachusets: Oelgeschlager, Gunn and Hain, 1980. p. 19-35.

LEDERER, K., (ed.). Human needs: a contribution to the current debate. Massachussets: Oelgeschlager, Gunn and Hain, 1980.

LUKÁCS, G. La scuola di Budapest. AUT AUT: Rivista di Filosofia e di cultura, Florença, v. 157/158, p. 184-185, 1977. 
MARCUSE, H. Ideologia da sociedade industrial. 5.ed. Trad. G. Rebuá. Rio de Janeiro: Zahar, 1979.

MARX, K. Manuscritos econômico-filosóficos. Trad. José Carlos Bruni et al. São Paulo: Abril Cultural, 1978. (Os Pensadores)

MARX, K. O capital: crítica da economia política. Trad. R. Sant'Anna. Rio de Janeiro: Civilização Brasileira, 1980. v. 1

SPRINGBORG,P. The problem of human needs and the critique of civilization. London: George Allen and Unwin, 1983. 